\title{
Clinical and immunological investigations of respiratory disease in workers using reactive dyes
}

\author{
A DOCKER, ${ }^{1} \mathrm{~J}$ M WATTIE, ${ }^{1}$ M D TOPPING, ${ }^{2} \mathrm{C}$ M LUCZYNSKA ${ }^{2}$ \\ A J NEWMAN TAYLOR, ${ }^{3}$ C A C PICKERING, ${ }^{4}$ P THOMAS, ${ }^{5}$ D GOMPERTZ ${ }^{2}$
}

From the Employment Medical Advisory Service, ${ }^{1}$ Health and Safety Executive, Manchester and Leicester, Occupational Medicine and Hygiene Laboratory, ${ }^{2}$ Health and Safety Executive, London NW2 6LN, Brompton ${ }^{\circ}$ Hospital, ${ }^{3}$ London, Wythenshawe Hospital, ${ }^{4}$ Manchester, and Medical Division, ${ }^{5}$ Health and Safety Executive ${ }_{\mathbb{D}}$ Bootle, Lancs, UK

ABSTRACT A questionnaire survey of over 400 workers handling reactive dyes showed that ove $15 \%$ had work related respiratory or nasal symptoms. Forty nine employees with symptoms wer\& referred to chest clinics for detailed assessment. It was considered that in 19 the symptoms could be attributed to an irritant response to a variety of chemicals, including hydrochloric acid vapous sulphur dioxide, and reactive dyes. Symptoms in 24 were attributed to an allergic reaction to specific agent; in most (21) to one or more reactive dyes. Two patterns of allergic lower respiratorg symptoms were identified; an immediate response of short duration and a longer lasting response्ठ usually of several hours, sometimes accompanied by nocturnal asthma. A radioallergosorbent tes (RAST) screen containing the most commonly used reactive dyes was used to detect specific IgE Allergic symptoms to reactive dyes were strongly associated with specific IgE (17/21 employees) an atopy (18/21). Irritant symptoms were also associated with atopy (13/19) but only weakly associated with specific $\operatorname{IgE}(7 / 19)$.

Asthma due to reactive dyes was first described in 1978 when four patients, employed in weighing out dye powders were shown to have positive bronchial challenges to dye powders. ${ }^{1}$ Positive skin prick tests to solutions of dyes and a positive radioallergosorbent test (RAST) to dyed paper discs suggested that the dyes were acting as haptens, provoking an IgE mediated hypersensitivity reaction. Subsequently Kalas and Runstukova found that eight of 106 textile workers exposed to reactive dyes had symptoms of occupational asthma. ${ }^{2}$

Our study followed up two separate incidents involving reactive dyes, one in Manchester and the other in Leicester. In Manchester two dyehouse operatives were brought to the attention of the Employment Medical Advisory Service by their trade union safety representative. They complained of recurrent severe nasal blocking which they attributed to Procion MX dye powders. In addition, both workers gave histories of exercise induced asthma. In Leicester a dyehouse employee presented with asthma which he

Accepted 13 October 1986 (C) Crown copyright 1986. attributed to reactive dyes. He had been advised bo his trade union to consult his local Employment Med ical Adviser. Two and a half years previously a cof league from the same dyehouse had been investigate for occupational asthma. Inhalation testing with Levafix orange reactive dye provoked an asthmate response; the dye was subsequently withdrawn from his place of work. This man's death at work with asthma gave urgency to this study.

The first phase of the study was to identify, by means of a questionnaire administered by a physt cian, those dyehouse operatives with work relate upper and lower respiratory tract symptoms. Symp tomatic employees identified by the questionnaifes were referred to one of two chest physicians whig investigated the nature of their symptoms, their sevep ity, relation with work, and the possible causative agents. The study included an estimate of the prevo lence of specific IgE to dye-human serum albumi conjugates (dye-HSA) as a measure of immunologica response in employees exposed to reactive dyes, and to relate this to symptoms, atopy, and smoking.

In the present paper we report the clinical ang immunological findings on the employees referred 
the chest clinics and data on the population from which they were drawn. The study was not an epidemiological survey; the first phase was designed primarily to identify symptomatic workers for detailed clinical investigation. The criteria for selection of workers for the clinical study differed somewhat between the areas studied and therefore the descriptions of the two populations are presented separately.

\section{Materials and methods}

\section{STUDY GROUPS}

All the dyehouses in the Manchester and Leicester areas were identified from HM Factory Inspectorate's records. Each was contacted to determine whether reactive dyes were in use. In each factory using reactive dyes all workers who at the time of the study were exposed to dye powders were included. In Manchester workers who had been exposed to dyes in the past but were not now exposed were also invited to participate in the study. In Manchester 196 employees were identified in a total of 22 dyehouses and in Leicester 218 in 30 dyehouses.

\section{JOB CATEGORY}

Employees were grouped into four exposure groups depending on their exposure to dye powders.

Group 1-Employees exposed to dye powders for most of their working day-for instance, dye storemen and mixers and weighers.

Group 2-Employees exposed to dye powders as part of their job such as dyers.

Group 3-Employees regularly exposed to small quantities of dyes such as laboratory staff and supervisors who were exposed to dye powders intermittently.

Group 4-Employees exposed in the past to dyes but currently working in jobs without dye exposure.

\section{QUESTIONNAIRE. INTERVIEW}

Two employment medical advisers, one for each area, administered to each employee a questionnaire about symptoms, smoking habits, and occupational history. Lower respiratory symptoms were defined as attacks of wheezing, chest tightness, or difficulty in breathing and were considered potentially associated with the work environment if better or less frequent when away from work. Nasal symptoms were defined as an itchy, runny, or blocked nose but excluding colds, and eye symptoms such as irritation or watering of the eyes, but excluding colds. These were considered to be potentially associated with the work environment if they were better or less frequent when away from work. Blood was taken for the measurement of specific IgE antibody. On completion of the questionnaire, employees in Manchester considered by the interviewing physician to have pronounced respiratory symptoms were referred to a chest physician for specialist appraisal. In Leicester the following employees were referred for specialist appraisal: those with respiratory or nasal symptoms or both associated with dye exposure, those with pre-existing asthma, and asymptomatic individuals with a positive RAST to one or more of the dye-HSA conjugates.

\section{CLINICAL INVESTIGATION}

Two chest physicians, one for each area, investigated the employees referred to them; the history was directed specifically at the identification of upper and lower respiratory tract symptoms, their relation with work, time of onset, and duration. Skin prick tests were performed with the dye-HSA conjugates and common inhalant allergens. A further blood sample was taken for specific IgE measurement.

\section{IMMUNOLOGICAL INVESTIGATIONS}

Identification of reactive dyes in use-The management at each dyehouse supplied a list of reactive dyes currently in use. From the lists it was found that over 300 different dyes were in use in the 52 factories. Colour index (CI) numbers (these give the chemical structure of a dye) could be obtained for 164 of these but since some dyes had different trade names but the same CI number, the final list contained 125 dyes. Taking the number of employees at each dyehouse and the dye list supplied by the dyehouse, a list of dyes was drawn up from these 125 to which more than 70 workers were exposed; 42 dyes came into this category.

Preparation of conjugates-To $5 \mathrm{mg}$ of each dye in a glass vial was added $5 \mathrm{ml}$ of $2 \%$ HSA (Sigma A9511) in $50 \mathrm{mM}$ carbonate/bicarbonate buffer $\mathrm{pH}$ 9.6. The mixture was immediately dialysed against phosphate buffered saline (PBS) ( 2 L, 2 changes) for 24 hours at room temperature. The conjugates were then stored at $-20^{\circ} \mathrm{C}$ until used. For use in the RAST screen and skin prick tests equal volumes of dye-HSA conjugates were pooled as shown in table 1 .

Skin tests-Two per cent dye-HSA conjugate mixtures, prepared as described in table 1 , or $2 \%$ HSA were dialysed overnight at $4^{\circ} \mathrm{C}$ against Coca's solution. Under a stream of sterile air, $2.5 \mathrm{ml}$ of dialysed material were passed through a Millex filter fitted with a $0.2 \mu \mathrm{m}$ membrane (Millipore Ltd) into a sterile vial containing $2.5 \mathrm{ml}$ glycerol and $0.25 \mathrm{ml} 4 \%$ phenol. Prick test solutions to common inhalant allergens (B2 grass pollens, cat fur, and house dust mite) were purchased from Bencard. Skin prick tests were performed on the flexor surface of the forearm and read at 10 minutes. A reaction to dye-HSA conjugate was defined as any weal greater than any weal elicited by HSA, and atopy was defined as at least one weal to a 
Table 1 Grouping of dye-HSA conjugates for use in RAST and skin tests

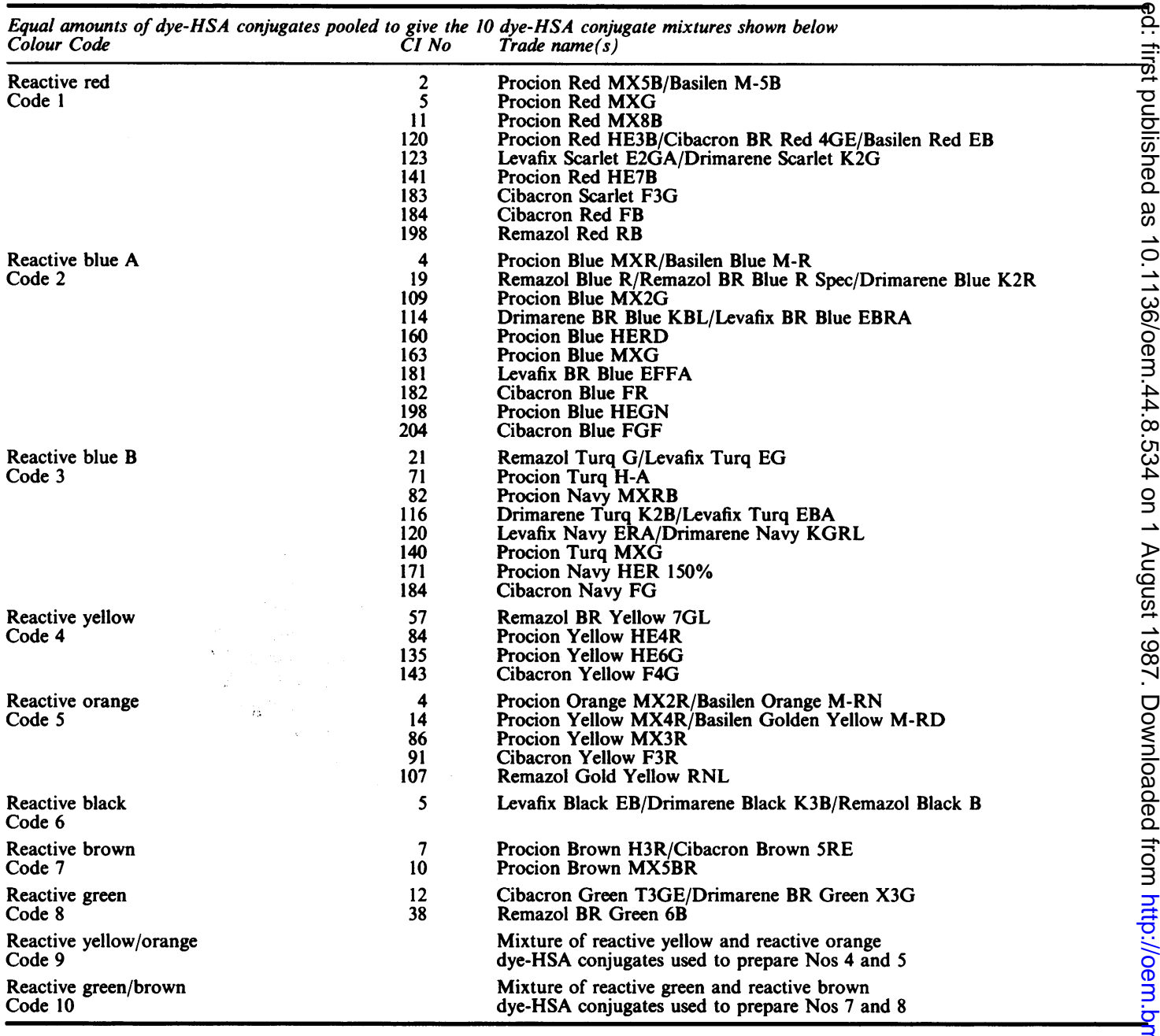

common antigen of at least $2 \mathrm{~mm}$ diameter after subtraction of the diameter of any weal elicited by the diluent control. Results were excluded if no reaction was elicited by any agent, including the histamine control, or if reactions were elicited by all agents, including the diluent and HSA controls.

Preparation of allergen discs-Paper discs (Schleicher and Schull No 589/3) were activated with cyanogen bromide. ${ }^{3}$ Activated discs $(600 \mathrm{mg}), 1 \cdot 5-1 \cdot 8$ $\mathrm{ml}$ of pooled $2 \%$ dye-HSA conjugates, or $1.5 \mathrm{ml}$ of $2 \% \mathrm{HSA}$ and $15 \mathrm{ml}$ of $0.1 \mathrm{M}$ sodium hydrogen carbonate were tumble mixed overnight at room temperature. The discs were then washed four times with PBS and stored at $4^{\circ} \mathrm{C}$ in RAST buffer solution (Pharmacia, Uppsala, Sweden).
Radioallergosorbent test (RAST)-Blood was taken from each employee when the questionnaire was administered; the serum was separated and stored at $-20^{\circ} \mathrm{C}$. Serum $(200 \mu \mathrm{l}$ of $1: 4$ dilution in PBS) was incubated overnight at room temperaturen with a dye-HSA conjugate disc and a further $200 \mu$ P with an HSA disc. Discs were washed three times with $1.5 \mathrm{ml}$ of $0.9 \%$ saline containing washing solution additive (Pharmacia, Uppsala, Sweden), then $50 \mu$ o ${ }^{125}$ I labelled rabbit antihuman IgE (Pharmaciaco Uppsala, Sweden) and $50 \mu$ of PBS were added. After a further overnight incubation at room temperature ${ }^{\infty}$ the discs were again washed three times with the washing solution and bound ${ }^{125} \mathrm{I}$ measured using gamma counter. All the assays were performed in 
duplicate. The results were expressed as a RAST per cent binding, defined as percentage of added counts per minute (cpm) bound to dye-HSA conjugate disc minus the percentage of added cpm bound to the HSA disc.

DATA ANALYSIS AND STATISTICAL METHODS The questionnaire and RAST data were analysed on a Honeywell DPS8 computer using the SPSS statistical package. Differences were tested by the $\chi^{2}$ test; a p value of 0.05 or less was regarded as significant.

\section{Results}

\section{RESPONSE TO SURVEY}

Questionnaires were completed between June and August 1985. None of the workers identified as being exposed to reactive dyes declined to take part. In Manchester 20 employees previously exposed to reacive dyes volunteered to take part in the study. Thus information on occupational history, smoking habit, and symptoms was obtained for each of the 414 employees (Manchester 196, Leicester 218). Blood samples were obtained for 405 of the employees.

\section{DETECTION OF SPECIFIC IgE}

Twenty employees from a different industry and with no possibility of exposure to dye powders were tested with each of the dye-HSA conjugate discs. The results showed that the net percentage binding to the dyeHSA conjugates discs - that is, the percentage binding to dye-HSA conjugate disc - the percentage binding to HSA disc did not significantly differ from zero (net percentage binding, $-0.0032 \%$; SD 0.082). Consequently, a RAST was considered positive if the net percentage binding to the dye-HSA conjugate disc was $2.5 \times$ SD of the survey sera binding to the HSA discs. This value was calculated and found to be $0.4 \%$. A previous study using individual dye-HSA
Table 2 Number of RAST positives to each of the pooled dye-HSA conjugates

\begin{tabular}{llllr}
\hline & & & \multicolumn{2}{c}{$R A S T$ positives } \\
\cline { 4 - 5 } Disc No & & No of tests & No & $\%$ \\
\hline & & Manchester & & \\
1 & Red & 167 & 8 & $4 \cdot 8$ \\
2 & Blue A & 170 & 8 & $4 \cdot 7$ \\
3 & Blue B & 183 & 8 & $4 \cdot 4$ \\
$4,5,9$ & Yellow/orange & 193 & 10 & $5 \cdot 2$ \\
6 & Black & 67 & 2 & $3 \cdot 0$ \\
$7,8,10$ & Green/brown & 82 & 3 & $3 \cdot 7$ \\
Total & & 862 & 39 & $4 \cdot 5$ \\
& & Leicester & & \\
1 & Red & 206 & 16 & $7 \cdot 8$ \\
2 & Blue A & 208 & 10 & $4 \cdot 8$ \\
3 & Blue B & 179 & 8 & $4 \cdot 5$ \\
$4,5,9$ & Yellow/orange & 186 & 13 & $7 \cdot 0$ \\
6 & Black & 112 & 12 & $10 \cdot 7$ \\
$7,8,10$ & Green/brown & 143 & 3 & $2 \cdot 1$ \\
Total & & 1034 & 62 & 6.0 \\
\hline
\end{tabular}

conjugates showed that total IgE concentrations $<4000 \mathrm{KU} / \mathrm{L}$ did not affect the RAST percentage binding, except for one dye, Remazol Black B, which gave $0.5 \%$ binding at $750 \mathrm{KU} / \mathrm{L}^{4}$

Sera were tested with a dye-HSA conjugate disc if the dye list supplied by the firm indicated that the employee was exposed to one or more of the dyes included on the disc. Sera from employees exposed to both a yellow and orange dye were tested with the yellow/orange disc No 9; those exposed to either yellow or orange were tested with either disc No 4 or No 5 as appropriate. The same procedure was followed with green and brown discs Nos 7, 8, and 10. Table 2 gives the number of RAST tests carried out with the disc types and the number of positives.

\section{QUESTIONNAIRE AND SPECIFIC IgE DATA,} MANCHESTER

The questionnaire responses of the study group in Manchester are summarised in table 3. Twenty four

Table 3 Characteristics of the study group, questionnaire responses, Manchester

\begin{tabular}{|c|c|c|c|c|}
\hline & $\begin{array}{l}\text { Whole } \\
\text { population } \\
(n=196)\end{array}$ & $\begin{array}{l}\text { Work related } \\
\text { respiratory } \\
\text { or nasal, both, } \\
\text { symptoms } \\
(\dot{n}=53)\end{array}$ & $\begin{array}{l}\text { Other } \\
\text { symptoms } \\
(n=44)\end{array}$ & $\begin{array}{l}\text { Asymptomatic } \\
(n=99)\end{array}$ \\
\hline $\begin{array}{l}\text { Mean age (years) } \\
\text { No (\%) male employees } \\
\text { Mean employment in current job (years) } \\
\text { No (\%) current smokers } \\
\text { No }(\%) \text { exposure group } 1 \\
\text { No }(\%) \text { exposure group } 2 \\
\text { No (\%) exposure group } 3 \\
\text { No }(\%) \text { exposure group } 4 \\
\text { No (\%) positive RAST to any dye albumin conjugate* } \\
\text { No (\%) work related respiratory symptoms with or } \\
\text { without nasal symptoms } \\
\text { No }(\%) \text { work related nasal symptoms } \\
\text { No (\%) respiratory and nasal symptoms not associated } \\
\text { with work }\end{array}$ & $\begin{array}{l}36 \cdot 0 \\
193(98 \cdot 5) \\
8 \cdot 5 \\
105(53 \cdot 6) \\
41(20 \cdot 9) \\
99(50 \cdot 5) \\
36(18 \cdot 4) \\
20(10 \cdot 2) \\
21(10 \cdot 8) \\
24(12 \cdot 2) \\
29(14 \cdot 8) \\
44(22 \cdot 4)\end{array}$ & $\begin{array}{c}35 \cdot 1 \\
53(100) \\
8 \cdot 9 \\
32(60 \cdot 4) \\
15(28 \cdot 3) \\
19(35 \cdot 8) \\
8(15 \cdot 1) \\
11(20 \cdot 8) \\
9(17 \cdot 0)\end{array}$ & $\begin{array}{l}35 \cdot 3 \\
43(98) \\
10 \cdot 0 \\
20(45 \cdot 5) \\
8(18 \cdot 2) \\
23(52 \cdot 3) \\
9(20 \cdot 5) \\
4(9 \cdot 1) \\
3(6 \cdot 8)\end{array}$ & $\begin{array}{l}36 \cdot 7 \\
97(98) \\
7 \cdot 6 \\
53(53 \cdot 5) \\
18(18 \cdot 2) \\
57(57 \cdot 6) \\
19(19 \cdot 2) \\
5(5 \cdot 1) \\
9(9 \cdot 3)\end{array}$ \\
\hline
\end{tabular}

*Denominator less than total group. 
Table 4 Characteristics of the study group, questionnaire responses, Leicester

\begin{tabular}{|c|c|c|c|c|}
\hline & $\begin{array}{l}\text { Whole } \\
\text { population } \\
(n=218)\end{array}$ & $\begin{array}{l}\text { Work related } \\
\text { respiratory } \\
\text { or nasal, both, } \\
\text { symptoms } \\
(n=21)\end{array}$ & $\begin{array}{l}\text { Other } \\
\text { symptoms } \\
(n=22)\end{array}$ & $\begin{array}{l}\text { Asymptomatic } \\
(n=175)\end{array}$ \\
\hline $\begin{array}{l}\text { Mean age (years) } \\
\text { No (\%) male employees } \\
\text { Mean employment in current job (years) } \\
\text { No (\%) current smokers } \\
\text { No }(\%) \text { exposure group } 1 \\
\text { No }(\%) \text { exposure group } 2 \\
\text { No }(\%) \text { exposure group } 3 \\
\text { No }(\%) \text { positive RAST to any dye albumin conjugate* } \\
\text { No }(\%) \text { work related respiratory symptoms } \\
\text { with or without nasal symptoms } \\
\text { No }(\%) \text { work related nasal symptoms } \\
\text { No }(\%) \text { respiratory and nasal symptoms not } \\
\text { associated with work }\end{array}$ & $\begin{array}{l}37 \cdot 6 \\
216(99) \\
10 \cdot 1 \\
108(49 \cdot 5) \\
33(15 \cdot 1) \\
155(71 \cdot 1) \\
30(13 \cdot 8) \\
28(13 \cdot 3) \\
10(4 \cdot 6) \\
11(5 \cdot 0) \\
22(10 \cdot 1)\end{array}$ & $\begin{array}{l}37 \cdot 3 \\
20(95 \cdot 2) \\
9 \cdot 5 \\
13(61 \cdot 9) \\
4(19 \cdot 0) \\
15(71 \cdot 4) \\
2(9 \cdot 5) \\
8(38 \cdot 1)\end{array}$ & $\begin{array}{l}34 \cdot 9 \\
22(100) \\
11 \cdot 6 \\
12(54 \cdot 5) \\
2(9 \cdot 1) \\
18(81 \cdot 8) \\
2(9 \cdot 1) \\
6(27 \cdot 3)\end{array}$ & $\begin{array}{c}38 \cdot 0 \\
174(99 \cdot 4) \\
10 \cdot 0 \\
83(47 \cdot 4) \\
27(15 \cdot 4) \\
122(69 \cdot 7) \\
26(14 \cdot 9) \\
14(8 \cdot 3)\end{array}$ \\
\hline
\end{tabular}

*Denominator less than total group.

employees reported work related lower respiratory symptoms with or without nasal symptoms and 29 work related nasal symptoms only. Forty four reported respiratory or nasal symptoms or both which did not improve during periods away from work. Comparison between those with work related symptoms and asymptomatic employees showed no difference in age, duration of employment in current job, smoking status, or exposure group. Specific IgE to dye-HSA conjugates, however, was twice as common in those with work related symptoms but this difference was not statistically significant. Comparison of specific IgE with exposure categories 1-3 showed that $22 \%(9 / 41)$ of the highest exposure group (group 1) had specific IgE compared with $4 \%$ $(4 / 101)$ and $9.5 \%(4 / 42)$ in groups 2 and 3 respectively. The observation that nine of the 20 employees in group 4-that is, those who had handled dyes in the past but were currently working in jobs without dye exposure-had specific IgE to dyeHSA conjugates suggests that at least in some of these employees sensitisation to dyes may have been a contributory cause for their relocation. On the basis of their response to the questionnaire, 23 employees in this area were considered to have work related respiratory symptoms that warranted referral to a chest clinic.

\section{QUESTIONNAIRE AND SPECIFIC IgE DATA, \\ LEICESTER}

The questionnaire responses of the study group in Leicester are given in table 4. Ten employees reported work related lower respiratory symptoms with or without nasal symptoms and 11 nasal symptoms only: 22 reported lower respiratory or nasal symptoms or both which did not improve during periods away from work. Comparison between those with work related symptoms and asymptomatic employees showed no difference in age, duration of employment in current job, smoking status, or exposure group. Specific IgE to dye-HSA conjugates, however, was significantly more common in those with work related symptoms, $38 \%(8 / 21)$ compared with $8 \cdot 3 \%(14 / 175)$ for the asymptomatic employees. On the basis of their response to the questionnaire, 36 employees were referred to a chest clinic; they were all those with lower respiratory symptoms whether or not this was related to exposure to dye (14 employees), those with nasal symptoms associated with dye exposure (11 employees), and those asymptomatic but RAST positive (11 employees).

\section{CLINICAL ASSESSMENT OF EMPLOYEES REFERRED} TO CHEST CLINICS

Of the 23 employees referred in Manchester, 22 attended the chest clinic and in Leicester 34 of the 36. In addition, two employees in Leicester were referred shortly after the asthmatic death as was another employee in Leicester who developed work'related respiratory symptoms four months after the survey. All the employees seen at the chest clinics were skin prick tested with dye-HSA conjugates 1-8 (see table 1 for list of dyes in each conjugate group) and common environmental allergens.

The 49 symptomatic workers were divided into four groups on the basis of the pattern of their clinical response (table 5). Twenty one had nasal or lower respiratory tract symptoms suggestive of a response caused by a specific allergic reaction to a reactive dye (group A, table 5). Eight had only nasal symptoms and four had lower respiratory symptoms, in some associated with nasal symptoms, that were immediate in onset and although of short (less than $\mathbf{3 0}$ minutes) duration, in some caused severe difficulty with breathing. These symptoms were distinguished by the specificity of the provoking factor (an identified reactive dye) from the similar "irritant" symptoms that were provoked by a variety of chemicals. In addition 
Table 5 Symptomatic employees seen at chest clinics. Relation between specific IgE, smoking, atopy, and symptoms

\begin{tabular}{|c|c|c|c|c|c|}
\hline & \multirow[b]{2}{*}{ No } & \multicolumn{2}{|c|}{ IgE to any dye-HSA conjugate } & \multirow[b]{2}{*}{ Smoking } & \multirow[b]{2}{*}{ Atopy } \\
\hline & & Skin prick test & $R A S T$ & & \\
\hline $\begin{array}{l}\text { Group A; } \\
\text { Work related allergic symptoms associated with dye } \\
\text { Nasal only } \\
\text { Asthma of short duration with/without nasal } \\
\text { "Typical" occupational asthma }\end{array}$ & $\begin{array}{l}8 \\
4 \\
9\end{array}$ & $\begin{array}{l}5 \\
3 \\
5(2 \mathrm{NT})\end{array}$ & $\begin{array}{l}5 \\
4 \\
8\end{array}$ & $\begin{array}{l}4 \\
2 \\
5\end{array}$ & $\begin{array}{l}7 \\
3 \\
8\end{array}$ \\
\hline $\begin{array}{l}\text { Group B: } \\
\text { Irritant reactions to dyes or other chemicals or both }\end{array}$ & 19 & 2 & 7 & 13 & 13 \\
\hline $\begin{array}{l}\text { Group C: } \\
\text { Work related allergic symptoms but not associated } \\
\text { with dye exposure: } \\
\text { Nasal only } \\
\text { Asthma with/without nasal }\end{array}$ & $\begin{array}{l}2 \\
1\end{array}$ & $\begin{array}{l}0 \\
0\end{array}$ & $\begin{array}{l}1 \\
0\end{array}$ & $\begin{array}{l}2 \\
0\end{array}$ & $\begin{array}{l}0 \\
1\end{array}$ \\
\hline $\begin{array}{l}\text { Group D: } \\
\quad \text { Allergic symptoms not associated with work }\end{array}$ & 6 & 0 & 1 & 4 & 5 \\
\hline
\end{tabular}

Table 6 Frequency of atopy, specific IgE, and smoking in asymptomatic employees compared with those with allergic symptoms and those with irritant symptoms

\begin{tabular}{|c|c|c|c|}
\hline & $\begin{array}{l}\text { Allergic } \\
\text { symptoms } \\
(n=21) \\
\text { No }(\%)\end{array}$ & $\begin{array}{l}\text { Irritant } \\
\text { symptoms } \\
(n=19) \\
\text { No }(\%)\end{array}$ & $\begin{array}{l}\text { Asymptomatic } \\
(n=269) \\
\text { No }(\%)\end{array}$ \\
\hline $\begin{array}{l}\text { Atopic } \\
\text { Current smokers } \\
\text { Specific IgE to any } \\
\text { dye-HSA conjugate }\end{array}$ & $\begin{array}{l}18(86) \\
11(52) \\
17(81)\end{array}$ & $\begin{array}{r}13(68) \\
13(68) \\
7(37)\end{array}$ & $\begin{array}{r}134(50) \\
20(7 \cdot 4)\end{array}$ \\
\hline
\end{tabular}

nine patients had histories suggesting asthma induced by one or more of the reactive dyes. In these patients asthmatic symptoms provoked by reactive dyes persisted for several hours or days after avoiding exposure. Asthma developed after a symptom free interval from initial exposure and deteriorated during the working week with improvement when away from work. In two of these individuals inhalation tests with reactive dyes had been found to provoke an asthmatic response. In this group of 21 patients there was a strong association both with atopy and specific IgE antibody to dye-HSA conjugates (table 6). The involvement of specific IgE antibody on the development of occupational asthma is supported by the observation that the employee who developed occupational asthma shortly after the survey was found at that time to have converted to a positive
RAST to two of the dye-HSA conjugates. He was immediately relocated and some 10 weeks later was asymptomatic and his RAST binding was considerably reduced (table 7).

Nineteen (group B, table 5) of the 49 complained of symptoms suggestive of a non-specific "irritant" response of their eyes, nose, and lower respiratory tract provoked by a variety of the chemicals used in the dyehouses. These included hydrochloric acid vapour, sulphur dioxide evolved from heated sodium hydrosulphite, and several of the reactive dyes. Symptoms complained of varied in severity from itching and running of the nose to cough with chest tightness developing within minutes of exposure and lasting up to 30 minutes from exposure. These symptoms were distinguished from allergic symptoms by the lack of specificity in the exposures provoking them. Table 6 shows that these "irritant" reactions are strongly associated with atopic status and only weakly associated with specific IgE to dye-HSA conjugates.

Three other patients (group C, table 5) had symptoms suggestive of occupational allergy not caused by reactive dyes: one had asthma associated with exposure to formaldehyde and two had nasal symptoms but it was not possible to identify an aetiological agent. In addition six others (group D, table 5) had symptoms of allergic reactions that were not associated with their work.

Eleven of the 36 employees from Leicester were

Table 7 Specific IgE results for employee who developed asthma shortly after completion of the survey

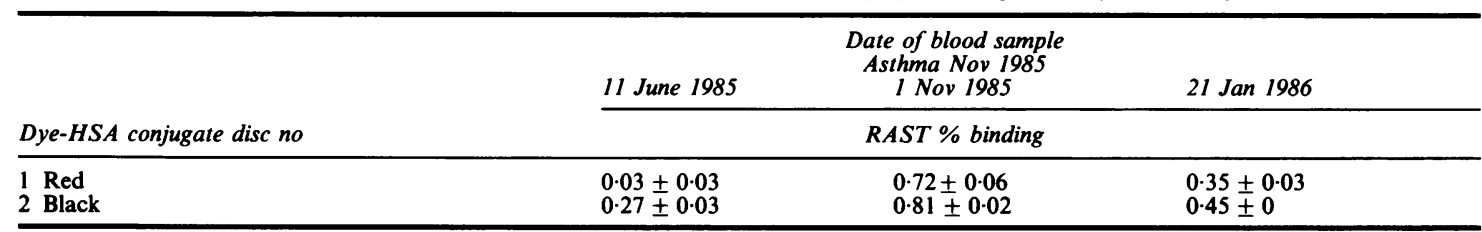

(RAST percentage binding greater than $0.4 \%$ indicates specific IgE.) 
asymptomatic on the basis of their questionnaire responses but had specific IgE to one or more of the dye-HSA conjugates. Clinical interview confirmed that they were asymptomatic and only two had positive skin tests to one or more of the dye-HSA conjugates. Two years previously one of these had worked as a dyehouse storeman. He gave a history suggestive of work related respiratory symptoms at that time. He was relocated and, although still engaged in dyeing, managed to avoid contact with dye powders and was now asymptomatic.

\section{SPECIFIC IGE IN ALLERGIC EMPLOYEES TO THE \\ VARIOUS DYE-HSA CONJUGATES}

Table 8 gives the number of positive skin prick tests and RASTs to each of the dye-HSA conjugates. There were differences in the skin test responses, nine of the 19 employees tested were positive to the orange dye-HSA conjugate (No 5) whereas there were fewer responses to blue, green, and brown conjugates. These differences were not so pronounced in RAST but nevertheless most responses were obtained with the yellow/orange dye-HSA conjugates (Nos 4, 5 \& 9).

Of the 21 allergic employees, 19 could associate their symptoms with exposure to particular dyes. For these individuals RAST was performed with dyeHSA conjugates prepared from the dyes they identified, in addition to the RAST screen. None of the employees gave a positive RAST to an individual dye-HSA conjugate and a negative response to the RAST screen.

\section{Discussion}

Dyehouse operatives are exposed to various respiratory hazards. 5,6 These include both allergenic substances and irritant vapours from chemicals used in the dyeing process such as sulphur dioxide and hydrochloric acid vapour. About $10 \%$ of our study group had pronounced respiratory or nasal symptoms; in half these were considered to be due to non-specifie irritant reactions and in the other half to specific allergic reactions. The major allergenic sources of ex posure in the dyehouses are the reactive dyes; these? were implicated as causative agents in 21 of $24 \mathrm{em}$ 을 ployees with allergic reactions. While not providing prevalence rates for the industry as a whole our dats suggest that respiratory reactions among dyehous@ operatives are an important problem.

We recognised three types of lower respiratory tract response provoked by inhaled materials in this group of dye house workers, irritant responses, and two types of allergic response. Irritant responses were differentiated from allergic responses by the lack of specificity in the agents provoking them. In the great majority of cases individuals with an allergic responses identified a limited number of reactive dyes aso provoking their symptoms. These allergic responses were of two types: an immediate response of short ${ }^{\ominus}$ duration and a longer lasting response, usually of several hours, which on occasions was associated with nocturnal asthma. It seems probable that this longe lasting response reflects an increase in non-specific airway responsiveness that develops as a consequence? of sensitisation to reactive dyes.

We were faced with an enormous range of dyes, anc for most the chemical structures are not published RAST testing of each employee with each dye was noe feasible, so we prepared dye-HSA conjugates of the most frequently used dyes and pooled those with the same basic colour to produce 10 pooled dye-HSAO conjugate mixes that were used in a RAST screen. As? a result we are less secure in the interpretation of the् IgE data than when workers are exposed to a limited $\mathrm{P}$ number of allergens, which may each be tested indi vidually. The RAST screen, however, identified. specific IgE in all the workers who were subsequently shown to have positive RASTs to conjugates of those dyes they identified as causing their symptoms. The RAST screen was positive for the majority, 17/2 $(81 \%)$ of employees with dye related allergic symp- -0

Table 8 Frequency of positive skin tests and RAST to dye-HSA conjugates in employees with allergy due to dye exposure

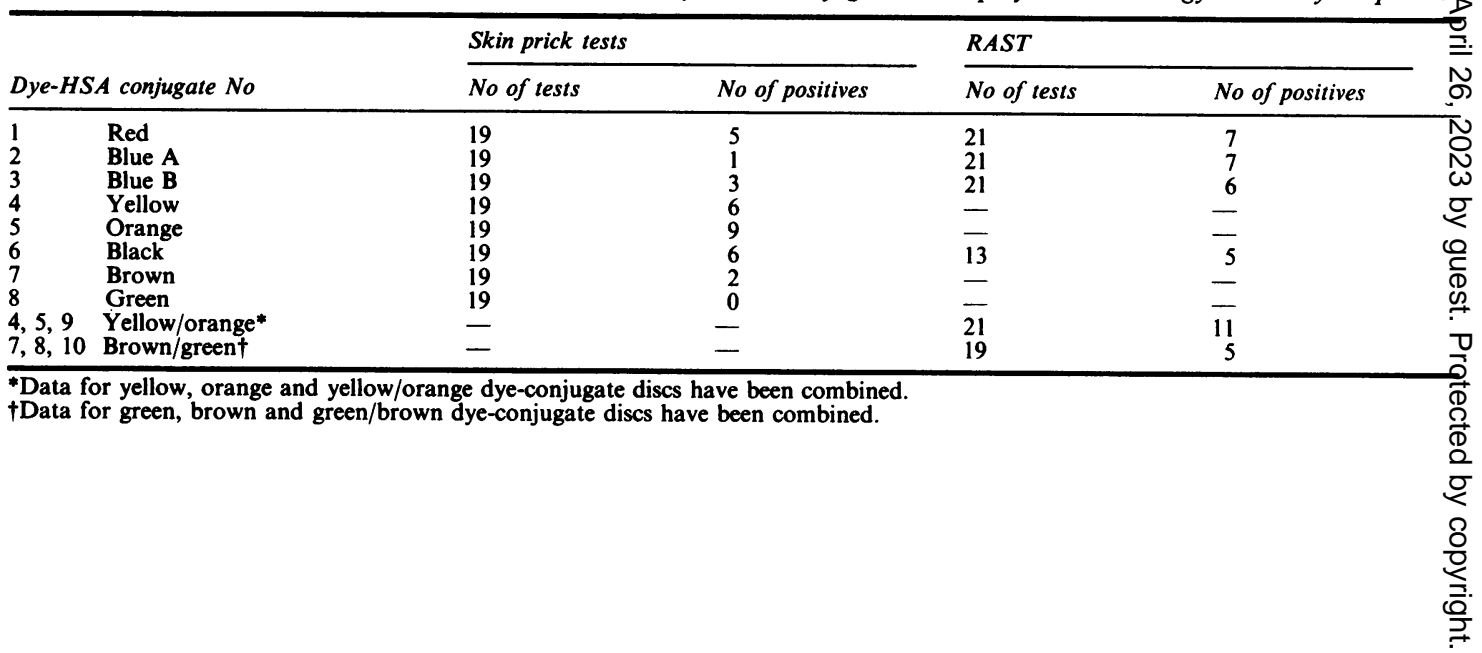


toms. None of the four RAST negative allergic employees gave a positive RAST when tested with individual dye-HSA conjugates; however, we still cannot be entirely certain that we have tested them with the relevant dye.

Many allergic employees responded to more than one dye-HSA conjugate, with nearly $50 \%$ showing immunological reactions, both by skin prick test and RAST to the yellow/orange dye-HSA conjugates, compared with only $25 \%$ responding to the green/ brown dye-HSA conjugates. This suggests that either the yellow/orange dyes are more immunogenic than the other dyes or they are dustier so that more is inhaled during their use. Since the cold reactive dyes react at lower temperatures, they would be expected to be more immunogenic, reacting more readily with protein in the lung. Anecdotal evidence from employees who have become sensitised bears this out, in that several implicated cold reactive dyes as causative agents.

The relations between the patterns of provoked respiratory symptoms, atopy, and specific IgE antibody to dye-HSA conjugates provides possible insight into the underlying mechanisms of the observed responses. Sixty eight per cent of those with irritant reactions and $86 \%$ of those with "allergic" reactions were atopic. It seems possible that the relatively high proportion of atopics among those experiencing irritant reactions reflects the increased bronchial responsiveness in atopics as compared with the non-atopic population. Atopy may also predispose to specific IgE antibody production to reactive dyes; specific IgE was identified in $81 \%$ of those with "allergic" symptoms but only $37 \%$ of those with irritant symptoms, suggesting that allergic symptoms may be the manifestation of a specific IgE mediated response to one or more reactive dyes.

At first sight our results appear to suggest that exclusion of atopic individuals would minimise the risk of sensitisation and respiratory disease. Atopy, however, is a poor predictor of subsequent response to reactive dyes. Between a third and a half of working populations are atopic. Of our study group of 414 , we can estimate that 150 to 200 atopic subjects would have to be excluded to prevent development of respiratory symptoms in 31 subjects. This policy would not have prevented the development of respiratory symptoms in the nine non-atopic subjects. Prevention of respiratory disease among dyehouse operatives will be achieved with better working practices and improved hygiene control to reduce the concentration of chemical vapour and dust from dye powders in the factory environment.

We thank Dr M Stern for the challenge test data and our HSE colleagues for helpful advice. Particular thanks for facilitating the survey are due to the Transport and General Workers Union, National Union of Hosiery and Knitwear Workers, and the Knitting Industry Federation.

Requests for reprints to: Dr M D Topping, Health and Safety Executive, 403 Edgware Road, London NW2 6LN.

\section{References}

1 Alanko K, Keskinen H, Bjorksten F, Ojanen S. Immediate-type hypersensitivity to reactive dyes. Clin Allergy 1978;8:25-31.

2 Kalas D, Runstukova J. The effect of working with ostazine dyes on the development of bronchiospasm and occupational bronchial asthma. Pracovny Lekarstvi 1980;32:103-9.

3 Ceska M, Eriksonn R, Vargo JM. Radioimmunoabsorbent assay of allergens. J Allergy Clin Immunol 1972;49:1-7.

4 Luczynska CM, Topping MD. Specific IgE antibodies to reactive dye-albumin conjugates. J Immunol Methods 1986;95:177-86.

5 Safe handling of dyestuffs in colour stores. Leeds: Health and Safety Executive, 1980.

6 Health and Safety Commission. Guidelines for the safe storage and handling of non-dyestuff chemicals in textile finishing. London: HMSO, 1985. 